ORIGINAL ARTICLE / ARTIGO ORIGINAL

\title{
Clinical management of the induction of labor in intrauterine fetal death: evaluation of incidence of cesarean section and related conditions
}

\author{
Manejo clínico na indução de parto de feto morto: \\ avaliação da incidência e condições associadas à cesariana
}

Maria Isabel do Nascimento', Alfredo de Almeida Cunha", Sandra Regina dos Santos Muri Oliveirall"

\begin{abstract}
Objective: To assess the incidence and conditions associated with cesarean section in a cohort of pregnant women with intrauterine fetal death (IUFD), and clinical management to anticipate the childbirth. Methods: It was a retrospective cohort study with 163 mothers with IUFD, at the second half of pregnancy, who were managed to anticipate childbirth using pharmacological preparations and/or a mechanical method (Foley catheter) in a teaching hospital in Rio de Janeiro State, Brazil. Cox regression was used to evaluate the effect of the clinical methods on the kind of delivery. Results: The Subgroups A (misoprostol or Oxytocin), B (misoprostol and Oxytocin), and C (Foley catheter alone or combined with misoprostol and/or Oxytocin) were formed according to the applied methods. Nine out of 163 cases ended with cesarean section. The incidence of cesarean section was 3.5 per 1,000 people-hours, meaning that a pregnant woman with IUFD had a $15.6 \%$ risk of cesarean section during the first 48 hours of clinical management to anticipate childbirth. The conditions significantly associated with the mode of delivery were placental abruption (HR: 44.97), having two or more previous cesarean deliveries (HR: 10.03), and mechanical method with Foley catheter (HR: 5.01). Conclusion: Cesarean section was an essential conduct in this cohort and followed previous cesarean delivery and placental abruption. The effect of the mechanical method on the abdominal route suggests that the Foley catheter method was used in the most difficult cases and that the surgery was performed to ensure maternal health.
\end{abstract}

Keywords: Incidence. Cesarean section. Labor, Induced. Survival analysis. Fetal death. Stillbirth.

'Departamento de Epidemiologia e Bioestatística da Universidade Federal Fluminense - Niterói (RJ), Brasil.

"Departamento de Ginecologia e Obstetrícia da Faculdade de Ciências Médicas da Universidade do Estado do Rio de Janeiro Rio de Janeiro (RJ), Brasil.

"'Coordenação da Clínica de Obstetrícia do Hospital Geral de Nova Iguaçu - Nova Iguaçu (RJ), Brasil.

Corresponding author: Maria Isabel do Nascimento. Rua Marquês do Paraná, 303, Anexo, 30 andar, Centro, CEP: 24033-900. Niterói, RJ, Brasil. E-mail: ysamaria@uol.com.br

Conflict of interests: nothing to declare - Financial support: none. 
RESUMO: Objetivo: Verificar a incidência e as condições associadas à cesariana em coorte de gestantes com feto morto e manejo clínico para antecipar o parto. Métodos: Estudo de coorte retrospectivo com 163 mães de feto morto intraútero, na segunda metade da gestação, que tiveram manejo clínico para antecipar o parto com administração de medicamentos e/ou por método mecânico com cateter de Foley, em um hospital escola do Estado do Rio de Janeiro, Brasil. A regressão de Cox foi empregada para avaliar o efeito entre os métodos clínicos e o modo de parto. Resultados: Os subgrupos A (misoprostol ou ocitocina), B (misoprostol e ocitocina) e C (cateter de Foley isolado ou combinado com misoprostol e/ou ocitocina) foram formados de acordo com os métodos administrados. Nove dos 163 casos terminaram em cesariana. A incidência de cesariana foi de 3,5 por 1000 pessoas-hora, significando que uma gestante com óbito fetal teve um risco de $15,6 \%$ de parto por cesárea durante as primeiras 48 horas de manejo clínico para antecipar o parto. As condições significativamente associadas ao modo de parto foram duas ou mais cesáreas prévias (HR: 10,03), descolamento da placenta durante a indução (HR: 44,97) e o método mecânico com cateter de Foley (HR: 5,01). Conclusão: Os fatores associados ao parto por cesárea foram a cesárea prévia e a ocorrência de descolamento da placenta. O efeito do método mecânico sugere que ele foi usado nos casos mais difíceis e a cirurgia foi realizada para assegurar a saúde materna.

Palavras-chave: Incidência. Cesárea. Trabalho de parto induzido. Análise de sobrevida. Morte fetal. Natimorto.

\section{INTRODUCTION}

The fetal death itself does not constitute an indication for cesarean section ${ }^{1}$, therefore the surgery should be reserved for specific conditions, since it increases maternal morbidity without any fetal advantage ${ }^{2}$. In the absence of urgent attention for the immediate labor, management should be carried out according to the pregnant woman and her relatives' wish, taking into account the expecting behavior and labor induction with medicine as the main alternative for finishing the pregnancy through the vaginal route 3 . Deciding for the induction depends on some conditions, such as reproductive history, gestational age, and cervix characteristics.

On the other hand, circumstances like high maceration degree of the fetal body ${ }^{4}$, labor obstructed by macrosomia or shoulder dystocia ${ }^{5}$, and center-total placenta previa ${ }^{6}$ make the abruption of the baby harder, requiring more invasive maneuvers to finish gestation through the vaginal route. Ethical questions and psychological burden, which include performing surgeries that destroy fetal structures, discourage its indication, so for some situations the only alternative left is the cesarean section ${ }^{5}$.

According to the Brazilian Ministry of Health (MS $)^{1}$, cesarean section in the stillbirth can be exceptionally indicated in situations like center-total placenta previa, cesareans of repetition, and placenta abruption with risk of coagulopathy. In the country, the cesarean section proportion is higher than that acceptable by the World Health Organization (WHO) ${ }^{7}$, it was the delivery 
choice of $27.5 \%$ of the stillbirths in $2010^{8}$. It is important to know the frequency and indications before the surgery performed in the fetal death considered plausible of induction and termination through the vaginal route. Thus, the objective of this study was to verify the incidence of cesarean sections and related conditions in a cohort of pregnant women with intrauterine fetal death (IUFD) and the management to anticipate labor with medicine and/or Foley catheter.

\section{METHODS}

This is a retrospective cohort study carried out through the review of medical records from mothers of stillbirths, attended between January 2005 and December 2008 in a teaching hospital in the Rio de Janeiro State, Brazil. This hospital institution is part of the Brazilian Unified Health System (SUS) and houses a reference obstetrics center for high-risk gestations where around 3,500 births happen, in average, per year.

\section{OUTCOME AND EXPOSURE OF INTEREST}

The studied outcome was the kind of labor reported in the medical record classified as cesarean section versus vaginal delivery. The main exposure of the study was the management of labor work that allowed creating three sub-cohorts based on the complexity of the managed schemes. Management of only one drug with the aim of preparing the cervix (misoprostol) or accelerating labor work (Oxytocin) was considered as a more simple scheme and was chosen as the reference category (Subgroup A). Due to the higher complexity of behavior, the administration of two drugs (Misoprostol and Oxytocin) was the base to compose the second category (Subgroup B). Finally, use of the mechanical method with Foley catheter alone or combined with drug therapy schemes formed a third category with a much more complex and mixed characteristic (Subgroup C).

\section{STUDY POPULATION}

Considering the definition of stillbirth based on the weight at birth $>499 \mathrm{~g}$ and/or in the gestational age of $\geq 22$ weeks $^{9}, 192$ mothers were qualified for the study and they met the inclusion criteria for using the scheme of cervix preparation, induction and/or acceleration of labor work, between January 2005 and December 2008. Twenty-nine mothers were excluded due to the following reasons: induction initiated with live fetus (10 cases); loss of information about fetal vitality in the beginning of induction ( 2 cases); twinning (1 case); induction initiated in the presence of premature placenta abruption (1 case); and cervical dilatation $>6 \mathrm{~cm}$ ( 15 cases). The study population included 163 mothers.

In the maternity routine, the drug therapy treatment to anticipate delivery of the stillbirth is done via vaginal misoprostol and/or endovenous Oxytocin. Use of misoprostol 
in the cohort was previously detailed ${ }^{10}$. Concisely, the initial dose corresponds to $25 \mu \mathrm{g}$, regardless of the gestational age. If there is a negative reaction, the administration of 50 or $100 \mu \mathrm{g}$ in intervals of six hours is considered. In the institution, misoprostol is immediately prescribed to cases of more than two previous cesarean sections. It is also avoided starting induction during night shifts. Medicine is indicated when immature cervix is present (dilatation $\leq 2 \mathrm{~cm}$, deletion $\leq 20 \%$, posterior positioning to the vaginal axis) and managed through the vaginal route alone or complemented with venous Oxytocin. On the other hand, the Oxytocin is preferentially used to accelerate labor work spontaneously initiated or to complement induction with misoprostol and/or Foley catheter after the cervix has become favorable. The drug is administered through the venous route with increasing doses, starting at $2 \mathrm{mUI} /$ minute until uterine activity similar to the physiological is found.

The intact amniotic membrane is the common criterion that guides the use of the mechanical method with Foley catheter. It is applied to promote cervix maturation in situations where there is not misoprostol available or when there is some kind of obstruction to its use. Generally, it is used the 12 or 14 catheter size with a $30 \mathrm{~mL}$ balloon that is juxtaposed positioned to the internal opening and traced until being expelled to the vaginal cavity. As mentioned, the method was applied alone combined with Oxytocin and/or misoprostol. If no answer is seen (cervical dilatation and/ or uterine activity) during the 48-hour term, application of other methods to finish pregnancy are reasoned. The possibility of reinsertion in the event of balloon expulsion was also rejected.

\section{DATA COLLECTION AND CHOSEN VARIABLES}

Data collection was done through the relation of stillbirths that happened during the study period, provided by the Health Municipal Secretariat. It helped identifying medical records that may be reviewed and be sources of information. Besides the kind of labor (cesarean section versus vaginal) and the management schemes to anticipate labor (Subgroup A, Subgroup B or Subgroup C), premature placental abruption (PPA) (yes; no), cesarean history (none; one; two or more) and center-total placenta previa were important for the study development due to its possible influence on indicating surgical labor ${ }^{1}$. Furthermore, the following co-variables were chosen as potential confusion factors: maternal age (up to 34 years old, $\geq 35$ years old); multiparous (up to two children, 3 or more children); nulliparous (yes, no); gestational age (until 28 weeks, > 28 weeks), malformation/polyhydramnio (yes, no), and maternal comorbidities (yes, no). The last ones include diabetes, chronic hypertensive vascular disease, hypertensive disease specific of pregnancy, maternal infections, among others.

With the aim of description from the baseline, data from the following variables were collected: admission at labor work (yes, no); Fetal Heartbeat (FHB) condition at admission (present, absent); integrity of the membranes (yes, no); maternal age (continuous variable in complete years); gestational age (continuous variable in complete weeks); residence town (place of the health institution, other places) and skin color (white; brown; black). The weight of the child at birth was also checked (in grams) (Table 1). 


\section{STATISTICAL ANALYSIS}

The survival analysis was applied to check the incidence of cesarean sections and related conditions. Kaplan-Meier method was initially used to perform the exploratory analysis of the chosen co-variables and to estimate the cesarean section incidence. The statistic significance in the exploratory phase was assessed by the log-rank test with 5\% level.

The follow-up period took another 48 hours, which was enough to end the pregnancies treated with cervix preparation, induction and/ or acceleration of the delivery ${ }^{11-14}$. Since the latency period related to induction methods is almost inexistent, zero time (t0) mark of the follow-up was the starting time for the induction, therefore there was no truncation at left.

Table 1. Baseline characteristics of the subgroups designated by type of treatment used for childbirth anticipation.

\begin{tabular}{|c|c|c|c|c|}
\hline \multirow{2}{*}{ Characteristics } & Subgroup A & Subgroup B & Subgroup C & Total \\
\hline & $\mathrm{n}(\%)$ & $\mathrm{n}(\%)$ & $\mathrm{n}(\%)$ & $\mathrm{n}(\%)$ \\
\hline Number of patients & $119(73.0)$ & $34(20.9)$ & $10(6.1)$ & $163(100)$ \\
\hline \multicolumn{5}{|l|}{ Maternal age (in years) } \\
\hline Mean & 26.0 & 25.1 & 25.1 & 25.8 \\
\hline SD & 7.34 & 7.98 & 6.52 & 7.41 \\
\hline \multicolumn{5}{|l|}{ Skin color ${ }^{\#}$} \\
\hline White & $16(14.2)$ & $3(8.8)$ & $0(0)$ & $19(12.1)$ \\
\hline Brown & $78(69.0)$ & $21(61.8)$ & $9(90.0)$ & $108(68.8)$ \\
\hline Black & $19(16.8)$ & $10(29.4)$ & $1(10.0)$ & $30(19.1)$ \\
\hline \multicolumn{5}{|l|}{ Gestational age (in weeks) } \\
\hline Mean & 31.0 & 30.1 & 31.6 & 30.9 \\
\hline SD & 5.62 & 4.27 & 4.69 & 5.30 \\
\hline \multicolumn{5}{|l|}{ Admission at labor } \\
\hline Yes & $44(37.0)$ & $0(0)$ & $0(0)$ & $44(27.0)$ \\
\hline No & $75(63.0)$ & $34(100.0)$ & $10(100.0)$ & $119(73.0)$ \\
\hline \multicolumn{5}{|l|}{ Intact membranes } \\
\hline Yes & $103(86.5)$ & $34(100.0)$ & $10(100.0)$ & $147(90.2)$ \\
\hline No & $16(13.5)$ & $0(0)$ & $0(0)$ & $16(9.8)$ \\
\hline \multicolumn{5}{|l|}{ Residence town } \\
\hline Place of the health institution & $50(42.0)$ & 19 (55.9) & $4(40.0)$ & $73(44.8)$ \\
\hline Other places & $69(58.0$ & $15(44.1)$ & $6(60.0)$ & $90(55.2)$ \\
\hline \multicolumn{5}{|l|}{ Child weight (in grams) } \\
\hline Mean & 1765.1 & 1542.9 & 1798.0 & 1720.5 \\
\hline SD & 1023.3 & 767.45 & 958.3 & 970.3 \\
\hline
\end{tabular}

\#including 157 mothers with complete data. SD: standard deviation. 
The cesarean section performance was considered a failure and marked by the childbirth time. Censures included delivery through the vaginal route and non-interrupted pregnancy at the end of the study follow-up (48 hours).

Cox regression was used to obtain the gross and adjusted Hazard Ratios (HR) by management subgroups of labor anticipation, and the chosen variables were those with $\mathrm{p}<0.25$. Regardless of the p-value, the exposures considered biologically important for the outcome under study were reassessed in the multi-diverse stage ${ }^{15}$ by applying Cox proportional risk model. In this last analysis phase, adjusted HR were obtained for factors that indicate cesarean sections including subgroups and confusion factors.

The statistical significance was assessed in the bivariate and multivariate stages through the likelihood reason test, considering the significance level of 25 and 5\% respectively. The $95 \%$ confidence intervals $(95 \% \mathrm{CI})$ were calculated.

The verification of the assumed global proportional risk and that of each variable of the final model was performed through Schoenfeld residue analysis, which was conducted using the R statistical program.

\section{ETHICAL ASPECTS}

The study followed Helsinki's Declaration principles and was approved by the Research Ethics Committee of the teaching hospital (Hospital Geral de Nova Iguaçu - HGNI), according to standard number 21/2009 (CAAE: 0023.0.316.000-09).

\section{RESULTS}

A total of 163 patients with stillbirths was analyzed. The obstetric exam at admission characterized absence of labor (73\%) and FHB (89\%) in most participants. Admissions with live fetus evolving to fetal death throughout hospitalization refer to cases of hypertensive syndromes (15/ 18 cases), extra-institutional abortive maneuver complicated due to infection ( $1 / 18$ cases), maternal syphilis with fetal malformation ( $1 / 18$ cases), and alterations of fetal annexes characterized due to umbilical cord around neck concomitant to true knot of cord.

The average cohort age was 25.8 years old ( $S D=7.41$ years old; variation of 14 to 46 years). The administration of only one drug was more prevalent to manage labor, therefore Subgroup A was composed of patients that used misoprostol (9.8\%) or Oxytocin (63.2\%), and Subgroup B by mothers that used both drugs (20.9\%). The other patients $(6.1 \%)$ were part of the Subgroup $\mathrm{C}$ (mechanical method), and the Foley catheter was used alone (1.2\%), combined with Oxytocin (3.1\%), with misoprostol (0.6\%), and misoprostol and/ or Oxytocin (1.2\%). Considering the group as a whole, the average of weight at birth was $1720.5 \mathrm{~g}$ ( $\mathrm{SD}=970.3 \mathrm{~g}$; variation: 465 to 5,760 g). The characteristics of the study population according to subgroups are presented in Table 1.

Proportion of cesarean sections was near $6 \%$ (9/163) corresponding to the incidence rate of 3.5 cesarean sections per 1,000 people/hour, meaning that a pregnant woman with 
IUFD and therapeutical management to anticipate delivery has a $15.6 \%$ accumulated risk of being submitted to the cesarean section throughout the first 48 hours of induction. Besides the censures from vaginal deliveries (147/163), seven patients were also censored (truncation at right) because the follow-up was stipulated in 48 hours and was concluded before the resolution of all pregnancies. However, these longer cases did not need the cesarean section.

At admission, all patients treated with cesarean section presented intact amniotic membranes and absent FHB. Only one of the cases (case 2) was found in labor at the moment of admission. Table 2 summarizes the characteristics of the cases treated with cesarean.

The bivariate analysis showed that age higher than 34 years old, parity of more than two children, nulliparity, and early gestational age reduced the risk of cesarean section. However, only the last one reached the criterion of $\mathrm{p}<0.25$, so it seems to be a potential confusion factor of the relationship between the delivery anticipation scheme with kind of labor. Half the group

Table 2. Characteristics of cases treated with cesarean section.

\begin{tabular}{|c|c|c|c|c|c|c|c|c|c|}
\hline \multirow[b]{2}{*}{$\begin{array}{l}0 \\
心 \\
0 \\
0\end{array}$} & \multirow[b]{2}{*}{ 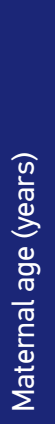 } & \multicolumn{3}{|c|}{ 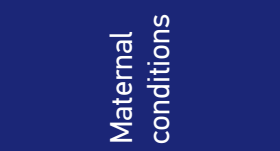 } & \multirow[b]{2}{*}{ 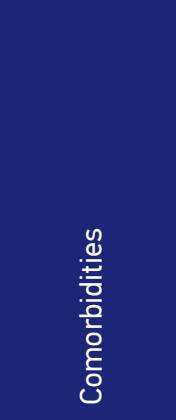 } & \multicolumn{4}{|c|}{ 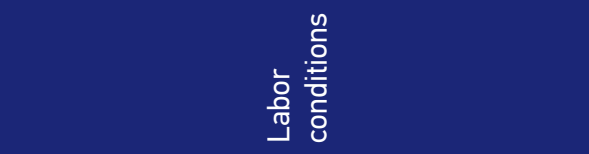 } \\
\hline & & $\begin{array}{c}\frac{\pi}{\pi} \\
\stackrel{0}{0} \\
\frac{\pi}{4} \\
0\end{array}$ & 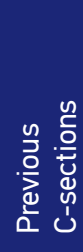 & 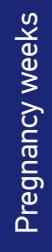 & & 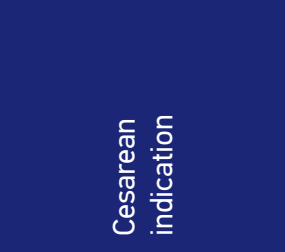 & 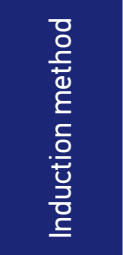 & $\begin{array}{l}\text { 는 } \\
\text { 을 } \\
\text { 들 } \\
\text { 은 } \\
\text { 을 }\end{array}$ & 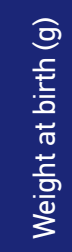 \\
\hline 1 & 19 & $1 / 0$ & 0 & 33 & $\mathrm{GH}, \mathrm{GD}$ & CPD & FC, M, O & 43 & 3220 \\
\hline 2 & 21 & $2 / 1$ & 0 & 33 & SLE & Coagulopathy & 0 & 4 & 1700 \\
\hline 3 & 27 & $5 / 3$ & 0 & 39 & $\mathrm{CH}, \mathrm{GD}, \mathrm{ITU}$ & CPD & 0 & 7 & 5760 \\
\hline 4 & 26 & $3 / 2$ & 2 & 31 & Absent & Induction failure & $\mathrm{FC}$ & 23,5 & 1100 \\
\hline 5 & 22 & $3 / 2$ & 2 & 28 & Malformation & Induction failure & $\mathrm{FC}$ & 21 & 1290 \\
\hline 6 & 17 & $1 / 0$ & 0 & 37 & $\mathrm{GH}$ & PPA during induction & 0 & 5,5 & 1500 \\
\hline 7 & 29 & $3 / 2$ & 2 & 30 & $\begin{array}{l}\text { Maternal } \\
\text { syphilis }\end{array}$ & Induction failure & 0 & 15 & 1350 \\
\hline 8 & 33 & $2 / 1$ & 1 & 37 & $\mathrm{CH}$, Diabetes & Induction failure & $\mathrm{FC}, \mathrm{O}$ & 25 & 3500 \\
\hline 9 & 38 & $2 / 1$ & 1 & 39 & Absent & Induction failure & $\mathrm{M}, \mathrm{O}$ & 47 & 3190 \\
\hline
\end{tabular}

GH: gestational hypertension; GD: gestational diabetes; CH: chronic hypertension; SLE: systemic lupus erythematosus; ITU: urinary tract infection; CPD: cephalo-pelvic disproportion; PPA: placenta premature abruption; FC: Foley catheter; M: misoprostol; 0: Oxytocin. 
presented some kind of comorbidity, raising the risk of cesarean section to $64 \%$ in comparison to the category 'absent comorbidities' but with non-significant statistically $p$ value $(p=0.465)$. It was seen that one in every four mothers had a history of previous $\mathrm{C}$-section, suggesting a higher risk for repetition of cesarean sections that is an effect evidenced by Cox regression $(\mathrm{HR}=9.57$; $95 \%$ CI $1.99-45.87$ ) for two or more cesareans combined with none. Placenta abruption in the induction was detected in $1.2 \%$ of the cases and was strongly associated with the cesarean section $(p=0.006)$. Based on the fact that only one drug was administered (Subgroup A), the schemes of labor management showed opposed effects. Subgroup B (misoprostol and Oxytocin) reduced the risk of cesarean $(\mathrm{HR}=0.27)$, while Subgroup C increased it almost three times $(\mathrm{HR}=3.82)$ even though it was not statistically speaking significant (Table 3).

In the multivariate stage, which was carried out by applying Cox model of proportional risks, the final model was achieved with PA occurrence and the cesarean history was positively associated with the kind of labor by cesarean section. The effect of the used schemes was similar to that previously found in the bivariate analysis, which suggest that Foley catheter seems to have been used in the worst cases and, therefore, ended up influencing on the decision of performing the C-section. The variable 'gestational age' was considered as biologically plausible of influencing in carrying out the surgical labor, even when there is IUFD. After adjustment, it was opted to keep it in the final model as a confusion factor of the relation between the labor anticipation schemes and the kind of labor (Table 4).

Schoenfeld residue analysis suggested that what was assumed as proportional risks of the global model was not violated $(\mathrm{p}=0.2251)$.

\section{DISCUSSION}

The great contribution of the study was to show that a pregnant woman with IUFD who has been chosen for cervix preparation and/or labor anticipation under routine conditions has a $15.6 \%$ accumulated risk of being submitted to C-section surgery in the first 48 hours of labor management. The results express the experience in a regional maternity institution of great size that, although a reference for high-risk pregnant women, works with its doors open for patients from several municipalities of the same area. Therefore, it arranges a heterogeneous spontaneous demand, mainly associated with obstetrics pathologies and antenatal conditions. Different from what was expected, there were cases that did not evolve through the vaginal route and the individualized obstetric surveillance was essential to detect threats to the maternal integrity and to guide intervention. It is worth mentioning that establishing the follow-up cohort point in 48 hours was based on review studies that showed most pregnancies with IUFD treated with the induction was solved in the established term ${ }^{11,12}$. This interval has been enough to solve cases of live fetuses treated both with misoprostol and with Foley catheter ${ }^{13,14}$. In addition, the global survival analysis practically did not change the found results since all cesarean sections were performed during a 48-hour period (non-published data). 
Table 3. Bivariate analysis: distribution of factors according to mode of delivery and crude Hazard Ratio in cohort of 163 mothers with fetal death and management for childbirth anticipation.

\begin{tabular}{|c|c|c|c|c|c|c|}
\hline \multirow[b]{2}{*}{ Factors } & \multicolumn{2}{|c|}{ Kind of delivery } & \multirow{2}{*}{$\begin{array}{l}\text { Total } \\
\text { n (\%) }\end{array}$} & \multirow{2}{*}{$\begin{array}{c}\text { Crude } \\
\text { HR }\end{array}$} & \multirow[b]{2}{*}{$95 \% \mathrm{Cl}$} & \multirow[b]{2}{*}{ p-value } \\
\hline & $\begin{array}{c}\text { Cesarean section } \\
\mathrm{n}(\%)\end{array}$ & $\begin{array}{c}\text { Vaginal } \\
\mathrm{n}(\%)\end{array}$ & & & & \\
\hline \multicolumn{7}{|l|}{ Maternal age } \\
\hline 35 years old and + & $1(11.1)$ & $23(15.0)$ & $24(14.8)$ & 0.68 & $0.08-5.48$ & 0.719 \\
\hline Up to 34 years old & $8(88.9)$ & $130(85.0)$ & $138(85.2)$ & 1 & & \\
\hline \multicolumn{7}{|l|}{ Multiparous } \\
\hline 3 children and + & $1(11.1)$ & $32(20.8)$ & $33(20.2)$ & 0.76 & $0.09-6.07$ & 0.793 \\
\hline Up to 2 children & $8(88.9)$ & $122(79.2)$ & $130(79.8)$ & 1 & & \\
\hline \multicolumn{7}{|l|}{ Nulliparous } \\
\hline Yes & $2(22.2)$ & $61(39.6)$ & $63(38.6)$ & 0.42 & $0.08-2.04$ & 0.282 \\
\hline No & $7(77.8)$ & $93(60.4)$ & $100(61.4)$ & 1 & & \\
\hline \multicolumn{7}{|l|}{ Age of gestation } \\
\hline$\leq 28$ weeks & $1(11.1)$ & $56(36.4)$ & $57(35.0)$ & 0.23 & $0.02-1.87$ & 0.170 \\
\hline$>28$ weeks & $8(88.9)$ & $98(63.6)$ & $106(65.0)$ & 1 & & \\
\hline \multicolumn{7}{|l|}{ Comorbidities } \\
\hline Yes & $5(55.6)$ & $78(50.6)$ & $83(50.9)$ & 1.64 & $0.43-6.28$ & 0.465 \\
\hline No & $4(44.4)$ & $76(49.4)$ & $80(49.1)$ & 1 & & \\
\hline \multicolumn{7}{|c|}{ Previous cesarean section } \\
\hline None & $4(44 . .4)$ & $128(83.1)$ & $132(81.0)$ & 1 & & \\
\hline 1 & $2(22.2)$ & $19(12.3)$ & $21(12.9)$ & 1.42 & $0.24-8.24$ & 0.690 \\
\hline 2 or + & $3(33.3)$ & $7(4.6)$ & $10(6.1)$ & 9.57 & $1.99-45.87$ & 0.005 \\
\hline \multicolumn{7}{|l|}{ PPA } \\
\hline Yes & $1(11.1$ & $1(0.7)$ & $2(1.2)$ & 23.69 & $2.43-230.15$ & 0.006 \\
\hline No & $8(88.9)$ & 153 (99.3) & $161(98.8)$ & 1 & & \\
\hline \multicolumn{7}{|l|}{ Malformation } \\
\hline Yes & $1(11.1)$ & $12(7.8)$ & $13(8.0)$ & 1.51 & $0.18-12.63$ & 0.699 \\
\hline No & $8(88.9)$ & $142(92.2)$ & $150(92.0)$ & 1 & & \\
\hline \multicolumn{7}{|l|}{ Induction } \\
\hline Subgroup A & $4(44.4)$ & $115(74.7)$ & $119(73.0)$ & 1 & & \\
\hline Subgroup B & $1(11.1)$ & $33(21.4)$ & $34(20.9)$ & 0.27 & $0.03-2.58$ & 0.261 \\
\hline Subgroup C & $4(44.4)$ & $6(3.9)$ & $10(6.1)$ & 3.82 & $0.91-16.01$ & 0.067 \\
\hline
\end{tabular}

*level of significance: 25\%. PPA: premature placental abruption; HR: hazard ratio. 
Table 4. Multivariate analysis and final model: factors associated to cesarean section in cohort of 163 mothers with fetal death and management for childbirth anticipation.

\begin{tabular}{l|c|c}
\multirow{2}{*}{ Factors } & \multicolumn{2}{|c}{ Final model } \\
\cline { 2 - 3 } Induction scheme & Adjusted HR & $95 \% \mathrm{Cl}$ \\
\hline Subgroup A & 1 & \\
\hline Subgroup B & 0.39 & $0.03-4.37$ \\
\hline Subgroup C & 5.01 & $1.04-23.87$ \\
\hline Placenta abruption & & $3.09-654.02$ \\
\hline Yes & 44.97 & \\
\hline Cesarean previous history & & $1.67-60.11$ \\
\hline Two or more & 10.03 & $0.02-1.88$ \\
\hline Gestational age $\leq 28$ & & 0.22 \\
\hline Yes
\end{tabular}

HR: Hazard Ratio.

In Brazil, there is little information concerning the frequency of cesarean sections due to induction time of the dead fetus labor. Descriptive data from 122 pregnant women assessed in the 1990s, in São Paulo, showed a 9.1\% C-section frequency in which most of them were associated with repetition of cesareans ${ }^{16}$. Considering elective inductions performed in women with live fetuses and without previous history that could affect the kind of delivery, the proportion of cesarean section corresponded to $11.8 \%$ in Latin America, between 2004 and $2005^{17}$. Besides the dead fetus, half of the present casuistry had an important morbid history that may have influenced on the frequency of surgeries found. The study also showed that PA occurrence, Cephalo-pelvic Disproportion (CPD), and use of the mechanical method with Foley catheter were positively associated with the surgical procedure. Cesarean section was indicated, most times, in the event of induction failure. The catheter was used in four out of the nine pregnancies that ended up in cesarean sections and was expelled before achieving the desired reaction. Despite this picture, the method was useful to solve six other cases that evolved through the vaginal route and it is still between the effective resources to use even in complex situations like IUFD. Results obtained through metanalysis point that, although Foley catheter is more effective when combined with Oxytocin, it is possible to use it alone ${ }^{18}$.

The present study calls the attention for the fact that, before a fetal loss, the active management to abbreviate pregnancy end can culminate with surgical deliveries, which, as mentioned, did not happen by chance. The Brazilian Ministry of Health ${ }^{1}$ assumes cesarean 
section in some conditions that present higher risk of hemorrhagic complications. Firstly, it is considered convenient in the presence of IUFD and low implantation of center-total placenta. In Holland, between 1990 and 2005, this combination was reported in only three cases performed with labor induction, cesarean surgery, and expecting behavior respectively, however surgery was indicated due to PA occurrence ${ }^{6}$. For the Brazilian Ministry of Health ${ }^{1}$, the PA occurrence also constitutes a reasoning to perform the $\mathrm{C}$-section due to the high risk of coagulopathy.

No case of center-total placenta previa integrated the present cohort. However, there were two cases of PA developed during labor management, one of which evolved through the vaginal route. Even though estimations presented a wide variability due to the low number of cases, PA occurrence implied in an instant and high accumulated risk of cesarean section. It is worth mentioning that most of the pregnant women had their fetus-annex conditions assessed through ultrasonography exam for fetal vitality. More specifically in these two cases, the ecographic signals confirmed fetal death, however they did not evidence retroplacental collections so probably the placenta separation happened concomitantly to the management of the labor work schemes.

A third justification accepted in Brazil for the IUFD surgical labor is the previous cesarean history ${ }^{1}$. The present investigation did not include women with history of one $(12.9 \%)$, two $(4.9 \%)$ or up to three $(1.2 \%)$ previous cesareans. Previous history of surgical delivery is one of the dilemmas faced in the obstetric practice. On one side, there is few scientific evidence that support finishing IUFD pregnancies through the C-section (with the exception of urgencies/emergencies). On the other, situations including fetal death generally happen before hospitalization (pre-delivery), in the presence of severe maternal comorbidities juxtaposed to repetition. These conditions both difficult the implementation of induction schemes, and also impede the wait for the spontaneous evolution. Facing maternal safety threat, the lack of scientific literature to perform C-section loses its meaning and decision taking of the route to finish pregnancy changes to the individual management. Personalizing management is the orientation found in several papers ${ }^{2,3,19}$. The abovementioned management considered the particularities of each case.

It is important to emphasize that cesarean sections rates have been increasing all over the world and, especially in Brazil, more than half of childbirths in 2010 happened through the high route ${ }^{20}$. There is evidence of increased risk of dead fetus after cesarean section delivery ${ }^{21}$, suggesting a complex cycle of maternal and perinatal morbimortality of difficult solution, which is frequently faced by health teams. Therefore, there is the risk of not only having to perform a later C-section, but also of a greater surgery like puerperal hysterectomy after a possible uterine rupture ${ }^{22}$. Although no case of uterine rupture has happened, it has been seen that previous history of two or more cesarean sections increased in ten times the risk of IUFD delivery through repetition of cesareans. Presence of IUFD and history of previous C-sections are two problems that seem to act together against the progression through vaginal route. 
On the other hand, it should not be forgotten that labor may not evolve as expected when opting for induction. In addition, provide the pregnant woman with an explanation of the risks and benefits of all treatment modalities, stimulate her participation and of her relatives in taking decisions and obtain the free informed consent are important measures, since all kinds of treatment impose some risk for the maternal safety in a scenario that has already been affected by fetal loss. For example, besides the difficulties imposed to the newborn abruption related to the fetal maceration degree ${ }^{4}$, there are thrombogenic substances produced in the placental tissue that enter in the maternal circulation and increase the risk of disseminated intravascular coagulation ${ }^{23}$, conferring a reserved prognosis for cases whose management is by observation. The unpredictable time in which the pregnant woman has to remain with the dead fetus in the uterus can trigger psychological instabilities, resulting in another disadvantage from the expecting management ${ }^{24}$. The list of problems that can be related to induction drug therapy schemes comprise increase of hemorrhagic complication risk, including PA, uterine rupture, coagulopathy, post-partum hemorrhage, and puerperal hysterectomy ${ }^{25}$.

It is important to consider that there are complications requiring carrying out maneuvers of difficult performance. For example, an alternative when there is obstructed delivery and total cervical dilatation can be the destructive surgeries of fetal parts ${ }^{26,27}$. The retrospective analysis of the procedures performed in India showed the presence of small $(27.7 \%)$ and extended (3\%) vaginal and cervical lacerations and other complications (3\%), besides two maternal deaths after craniotomy ${ }^{26}$. In general, such surgeries have not been part of the recent obstetrics practice. Maybe this is done to avoid damage related to the procedure itself or because they seem to configure a lost $\operatorname{art}^{28}$. The fact is that opportunities to put them into practice rarely happen, which impede the acquisition of skills, the formation of experts, the qualification of professionals, and learning dissemination. With the wide range of technological arsenal that is able in the recent obstetrics, a question that still remains is if it is worth trying to overcome such deficiency. Even the practice training in big centers abroad has low cost given the rarity of cases, so the only alternative that is left is training in mannequins ${ }^{5}$.

The present study has limitations. Firstly, the cohort was formed retrospectively from information that has been daily registered in medical records, i.e. without any aim for a research. However, the analysis was strict to complete data collected by two reviewers in different moments, providing improvements in information quality and minimizing the possibility of gauging errors. The incompleteness of some data prevented Bishop index calculation. The only option was using the cervix conditions (deletion and dilatation) to establish criteria and select mothers to enter in the study. Another question was the size of the cohort, which was not enough to carry out stratified analyses by subgroups and induction schemes. However, the alternative of including subgroups in the multi-varied analysis showed that the mechanical method seemed to constitute an important prognosis factor for the kind of delivery in this population. Even though it has been verified risk proportionality of the global model, the variable 'induction scheme' had a category 
with the refuted premise. It is believed that some cases are originated from the random fluctuation related to the low number of records ${ }^{29}$, so this is a possible explanation for the results found.

Although the mechanical methods have not been abandoned yet, they have been replaced by pharmacological methods or complemented by managing Oxytocin ${ }^{30}$. Although only $6.1 \%$ of the cases now assessed have used Foley catheter, this happened in a diversified way that probably is a reflex of the morbidity profile of the studies cohort, which included cases like the previous cesarean section that usually are excluded from effectiveness studies. Thus, despite the strong association found, findings should be interpreted with caution, since in this subgroup managements were individualized from the profile of every patient. The individualization of management based on the complexity of cases explains why Foley catheter was used alone, considering that the method is able of promoting not only the mechanical dilatation of the uterine cervix but also of stimulating the release of prostaglandins ${ }^{14,30}$.

The advantages of the study are due to the focus on the IUFD delivery, which is a problem that is still very little approached in the Brazilian scenario. Also, to the focus on induction methods, which still lack information in the great bases of information systems of mortality and live births in the country; and to the use of Cox regression to calculate instantaneous and accumulated risks.

\section{CONCLUSIONS}

It has been seen that the risk of carrying out cesarean sections during the first 48 hours of induction was of $15.6 \%$. The factors associated with cesarean sections were: having had two or more previous cesarean sections, having had placenta abruption during the induction, and having been submitted to the mechanical method with Foley catheter. The effect of this method suggests that it was used in the most difficult cases and the surgery was performed to ensure maternal safety.

\section{REFERENCES}

1. Brasil. Ministério da Saúde. Secretaria de Políticas de Saúde. Departamento de Gestão de Políticas Estratégicas. Área Técnica de Saúde da Mulher. Gestação de alto risco - Manual técnico. $3^{\text {a }}$ edição. Brasília: Ministério da Saúde, 2000. p. 67-68.

2. ACOG Practice Bulletin No. 102: management of stillbirth. Obstet Gynecol 2009; 113(3): 748-61.

3. Silver RM, Heuser CC. Stillbirth workup and delivery management. Clin Obstet Gynecol 2010; 53(3): 681-90.
4. Habek D. Delivery course of macerated stillborn fetuses in the third trimester. Fetal Diagn Ther 2008; 24(1): 42-6.

5. Steel A, Fakokunde A, Yoong W. Management of complicated second stage of labour in stillbirths: a review of the literature and lessons learnt from two cases in the UK. J Obstet Gynaecol 2009; 29(6): 464-6. 6. van der PloegJM, Schutte JM, Pelinck MJ, Huisjes AJ, van Roosmalen J, de Vries JI. Management of fetal death after 20 weeks of gestation complicated by placenta previa. J Matern Fetal Neonatal Med 2007; 20(3): 267-9. 
7. Brasil. Ministério do Planejamento, Orçamento e Gestão. Instituto Brasileiro de Geografia e Estatística (IBGE). Diretoria de Pesquisas. Coordenação de População e Indicadores Sociais. Indicadores Sociodemográficos e de Saúde no Brasil. Rio de Janeiro: IBGE, 2009.

8. Brasil. Ministério da Saúde. Departamento de Informações do Sistema Único de Saúde. Informações em saúde(DATASUS). Sistema de Informações sobre Mortalidade(SIM). Disponível em http: / / tabnet.datasus.gov.br/cgi/deftohtm.exe?sim/ cnv/ fet10uf.def. (Acessado em 12 de dezembro de 2012).

9. Brasil. Ministério da Saúde. Secretaria de Vigilância em Saúde. Secretaria de Atenção à Saúde. Manual de vigilância do óbito infantil e fetal e do Comitê de Prevenção do Óbito Infantil e Fetal. $2^{\mathrm{a}}$ edição. Brasília: Ministério da Saúde; 2009. p. 22

10. Nascimento MI, Cunha AA, Oliveira SR, Nunes GG, Alvarez FS, Villas Boas EL. Misoprostol use under routine conditions for termination of pregnacies with intrauterine fetal death. Rev Assoc Med Bras 2013; 59(4): 354-9.

11. Cunha AA. Induction after fetal death. Femina 2008; 36(1): 31-9.

12. Gómez Ponce de León R, Wing DA. Misoprostol for termination of pregnancy with intrauterine fetal demise in the second and third trimester of pregnancy - a systematic review. Contraception 2009; 79(4): 259-71.

13. Federação Latino-Americana de Sociedades de Obstetrícia e Ginecologia (FLASOG). Uso de misoprostol em obstetrícia e ginecologia. Disponível em: http:/ / www.misoprostol.org/File/Other_G_ FLASOG_Misoprostol_guidelines_Portugues.pdf. (Acessado em 12 de dezembro de 2012).

14. Oliveira MV, Oberst PV, Leite GK, Aguemi A, Kenj G, Leme VD, et al. Cervical Foley catheter versus vaginal misoprostol for cervical ripening and induction of labor: a randomized clinical trial. Rev Bras Ginecol Obstet 2010; 32(7): 346-51.

15. Olinto MTA, Victora CG, Barros FC, Tomasi E. Determinants of malnutrition in a low-income population: hierarchical analytical model. Cad Saúde Pública 1993; 9(Suppl 1): 14-27.

16. Aquino MMA, Guedes AC, Mesquita MRS, Hernandez M, Cecatti JG. Obstetrical management of fetal death. Rev Bras Ginecol Obstet, 1998; 20(3): 145-9.

17. Guerra GV, Cecatti JG, Souza JP, Faúndes A, Morais SS, Gulmezoglu AM, et al. Elective induction versus spontaneous labour in Latin América. Bull World Health Organ 2011; 89(9): 657-65.

18. Boulvain M, Kelly A, Lohse C, Stan C, Irion O. Mechanical methods for induction of labour. Cochrane Database Syst Rev 2001;(4): CD001233.

19. Schupp TR, Miyadahira S, Zugaib M. Qual é a conduta atual no óbito fetal. Rev Assoc Med Bras 2002; 48(4): 275-96.
20. Brasil. Ministério da Saúde. Departamento de Informações do Sistema Único de Saúde (DATASUS). Sistema de Informações sobre Nascidos Vivos (SINASC). Disponível em: http:/ / tabnet.datasus.gov.br/cgi/ deftohtm.exe?sinasc/cnv/nvuf.def. (Acessado em 12 de dezembro de 2012).

21. Gray R, Quigley MA, Hockley C, KurinczukJJ, Goldacre $\mathrm{M}$, Brocklehurst P. Caesarean delivery and risk of stillbirth in subsequent pregnancy: a retrospective cohort study in an English population. BJOG 2007; 114(3): 264-70.

22. Ramirez MM, Gilbert S, Landon MB, Rouse DJ, Spong CY, Varner MW, et al. Mode of delivery in women with antepartum fetal death and prior cesarean delivery. Am J Perinatol 2010; 27(10): 825-30.

23. Papp Z. Fetal Demise. In: World Association of Perinatal Medicine (WAPM), Matres Mundi International. Recommendations and guidelines for perinatal medicine. Disponível em: http://www.wapm.info/ Portals/0/recommendations_perinatal.pdf. (Acessado em 12 de dezembro de 2012).

24. Brasil. Ministério da Saúde. Secretaria de Atenção à Saúde. Departamento de Ações Programáticas Estratégicas. Gestação de alto risco: manual técnico. $5^{\mathrm{a}}$ edição. Brasília: Editora do Ministério da Saúde; 2010. p. 101-9.

25. Gómez Ponce de León R, Wing D, Fiala C. Misoprostol for intrauterine fetal death. Int J Gynaecol Obst 2007; 99(Suppl 2): S190-3.

26. Sikka P, Chopra S, Kalpdev A, Jain V, Dhaliwal L. Destructive operations--a vanishing art in modern obstetrics: 25 year experience at a tertiary care center in India. Arch Gynecol Obstet 2011; 283(5): 929-33.

27. Ifnan F, Jameel MB. Maternal morbidity and mortality associated with delivery after intrauterine fetal death. J Coll Physicians Surg Pak 2006; 16(10): 648-51.

28. Mukherj J, Kamilya G, Bhattacharyya SK. Caesarean section for the dead baby--an unhappy reality. J Indian Med Assoc 2007; 105(6): 316, 318-9.

29. Carvalho MS, Andreozzi VL, Codeço CT, Barbosa MTS, Shimakura SE. Análise de sobrevida: teoria e aplicações em saúde. Rio de Janeiro: Editora FIOCRUZ, 2005. p. 207-32.

30. Moraes Filho OB, Cecatti JG, Feitosa FEL. Methods for labor induction. Rev Bras Ginecol Obstet 2005; 27(8): 493-500.

Received on: 01/07/2013

Final version presented on: 10/16/2013

Accepted on: 11/13/2013 